\title{
The safest way to increase overall pitwall slope
}

\author{
SP Durkin Safescape, Australia \\ BT Moore Safescape, Australia
}

\begin{abstract}
The overall pitwall slope angle of an open pit mine is a critical engineering factor in determining stripping ratio in any given mine. The reduction of stripping ratio results in revaluation of every block of mineralised material within a resource. It generally increases the ore reserve thereby increasing resource utilisation and in most cases will result in improved net present value of a given orebody.

Slope stability risk analysis will generally determine the critical element of inter-ramp angle with other features around berm crest width and batter angle. The easiest way to impact overall pitwall slope without interfering with the inter-ramp slope is to reduce the width requirement of the ramp. There are many ways to do this. Safescape's patented Edge Protector product is a modular cantilever wall that creates a vertical front face to a rock bund. This results in a reduction of up to half of the road width taken up by rock bunds used as edge delineation for haul roads. This change has a positive impact on the economics and sustainability of most open pits. Various factors including depth, size of trucking fleet, optimised stripping ratio and inter-ramp slope all play a part in determining how much value can be achieved.
\end{abstract}

The Edge Protector system also reduces the likelihood of trucks driving over a rock bund. To penetrate a bund, trucks need to engage the soil force of the material immediately behind the barrier, thus reducing their speed. Mathematical analysis by The University of Western Australia and field testing has provided the authors with a way of providing a level of engineering confidence around truck interactions with rock bunds that was not previously possible.

Keywords: edge protection, risk, hazard, pit slope, safety

\section{Introduction}

Safescape Edge Protector (EP) was developed as a safety initiative to improve haul road edge protection in open pit mines. The design of EP allows haul roads to be narrower while maintaining or improving the safety properties. EP is a modular-filled polyethylene shell designed for ease of implementation, maintenance and reusability. Modules are secured together in a row along the edge of a haul road. These modules act to support loose rock situated on the base behind the unit and display a vertical front face inward towards the road. The vertical face of EP eliminates the risk of the truck mounting the edge protection as it would have been for a traditional bund in place where the tyres roll up the bund. If a collision should occur, EP is designed to deflect trucks or slow down the momentum as the bund absorbs the energy and provides resistive force. This system allows for a reduction in the width of traditional rock bunds by replacing the protruding edge of the bund with a vertical face.

Decreasing haul road widths throughout an open pit mine will increase overall pit slope without changing the inter-ramp slope angle and impacting the slope stability. Steepening the pit slope will have both environmental and economic impacts. Increasing the pit slope will determine the stripping ratio as well as potentially create access to additional ore at the bottom of the pit not available at lower development angles. Mining rate is a critical element in the early life-of-mine and reaching ore earlier in the life-of-mine would be beneficial. The economic impacts were evaluated in a hypothetical mining study by Whittle Consulting Pty Ltd. In 2019, Whittle Consulting Pty Ltd added an evaluation of the potential effects of EP on $\mathrm{CO}_{2}$ emissions to their report and revisited the initial results. 


\section{$2 \quad$ Edge protector design and development}

\subsection{Design criteria}

Safescape recognised that by replacing traditional rock bunds with a vertical face product, haul road safety would be improved and potential for economic benefit existed. Design criteria had to meet the safety initiative of the product while considering the manufacturing process and mining environment. Manufacturing along with product installation needed to be quick and economical. Additional value would be added from a simple installation process and the ability for the product to be used in multiple applications.

The concept of the product is a vertical face to eliminate tyres from rolling up the EP supported by loose rock at the base of the module. Rock is required so that if a truck collides with EP, enough force is applied back onto the truck from the barrier to prevent the vehicle from pushing EP over the edge. EP modules are not bolted to the ground and under impact will move and push against the rock support. It was critical that EPs have the added rock to contribute weight to the structure. As a result, EP was required to support the weight of the rock load. The polyethylene shells need to be strong enough to resist collision while proving durable for harsh mining conditions. It is expected that units may be damaged under significant impact. These are easily replaceable and less costly than the potential risk of injury and significant damage to equipment.

Safescape specialises in the design and manufacturing of plastic and composite products for use in the mining industry. This background determined the manufacturing process of EP from plastic and composite materials. EP is produced from a rotational mould at Safescape's manufacturing facility. The mould uses polyethylene to create a plastic shell. The polyethylene modules are corrosion resistant, highly visible, resistant to thermal stress and easy to transport and re-use onsite.

\subsection{Theoretical application studies}

\subsubsection{Safety barrier application}

A theoretical analysis by Fowkes \& Bassom (2015) was conducted to determine the effect of the EP as a replacement for traditional rock bunds as seen in Figure 1. The goal of the initial works was to understand the interaction of a vehicle with the EP and loose rock behind the barrier.

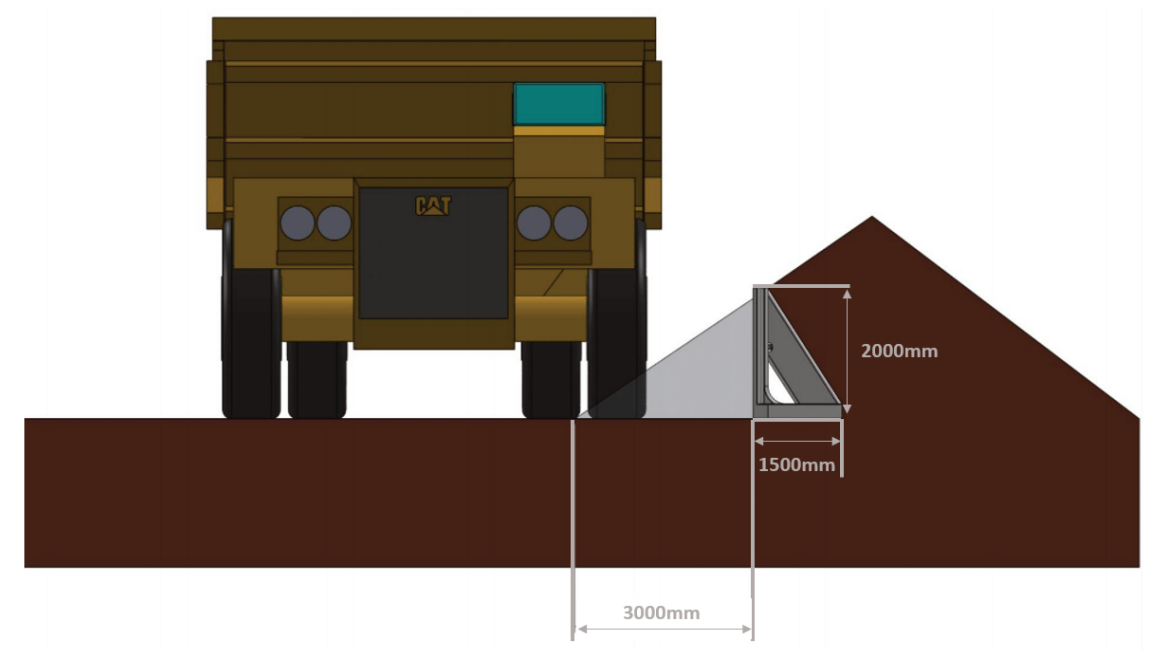

Figure 1 Edge Protector replacing a traditional rock bund

The worst-case scenario of a head-on collision with EP was initially assessed in the study. The analysis focused on the impact on the product, the resistive forces involved and the potential effect on the vehicle and operator. The worst-case scenarios analysis of low angle impacts were investigated which are more likely to occur onsite. When a vehicle approaches and collides with EP at lower angles, it is more likely to be directed back onto the haul road with less resistive forces required to stop the vehicle. 
Results demonstrate that EP is effective in minimising the risk of a truck rollover. The stopping distance of a vehicle was calculated as function of the EP dimensions and the height, specific gravity and yield strength of the rockfill supporting the barrier (Durkin et al. 2016). The theoretical results indicating that the soil within the plastic flow wedge-shaped zone is the primary factor in determining the soil force associated with yielding and the soil resistance force (as a function of speed) were recommended to be field-tested to confirm theoretical results. Onsite testing should also be conducted to evaluate the change of conditions including rock compositions, compression and in varying environmental conditions.

\subsubsection{Economic application}

Economic benefits of EP were studied by Whittle Consulting Pty Ltd who applied the product to a hypothetical mining case study. The case study investigated three scenarios; a base case with traditional rock bunds, Case 1 with EP and a standard loose rock height, and Case 2 with EP and a reduction of the height and width of the rock. A $6.3 \mathrm{~m}$ wide haul truck (CAT ${ }^{\circledR} 785 \mathrm{c}$ ) multiplied by a two-way factor of 3.5 plus $7 \mathrm{~m}$ for the berm plus drain was applied to the base case (Redwood 2016).

The three cases were applied to the modelled Marvin orebody created by Norm Hanson to determine the magnitude of the economic impact. This orebody contains high-grade copper at the base of the structure moving into high-grade gold towards the top of the deposit. The overall block size of this model is $20 \times 20 \times 20 \mathrm{~m}$ with a 10-year mine life. For each case study, the Geovia Whittle software (Geovia Whittle ca. 2019) applied a set of basic assumptions to the four-phase open pit design. A Skin Analysis technique was used to select the mine design that would produce the greatest net present value (NPV) for mine development.

A whole system approach is required to calculate the complete benefits of reducing the widths of haul roads and the impact on the mean pit slope. This approach would consider small changes in the mine operation and tie into the time-value. The approach to time-value calculations was to discount cash flow to produce a comparable NPV as the primary measure of the financial benefits, reflective of changing conditions. A capital of AUD 600M was allotted for mine development and applied to the cases studies. Using the Simultaneous Optimizer (SIMO) function in the Geovia Whittle software, an optimised mining, stockpiling and processing schedule was produced.

\subsubsection{Environmental application}

In 2019, Whittle Consulting Pty Ltd added an evaluation of the effect of EP on the diesel usage by haul trucks and other in-pit equipment and the subsequent $\mathrm{CO}_{2}$ emissions to the existing study. The diesel consumption model used in the current assessment was identical to that used in the Whittle Consulting Pty Ltd case study (Redwood 2018).

To calculate the consumption, diesel consumed is divided between equipment that scales with tonnes of mined material (e.g. excavators) and equipment that scales with tonnes of moved material. In the model, $-0.34 \mathrm{~L}$ of diesel is used per tonne of mined material plus $5.75 \mathrm{~L} / \mathrm{t} \cdot \mathrm{rkm}$ where $\mathrm{rkm}$ is a kilometre of loaded equipment to destination and unloaded equipment returning to the operation location.

$\mathrm{CO}_{2}$ emission reductions from a mine site processing plant may be observed where EP units are increasing the pit slope and influencing the total ore produced over the life-of-mine, though this has not been assessed.

\subsection{Physical testing}

To test EP in a lifelike scenario, eight tests were conducted on an EP barrier. Oxide and fresh rock were used to create various heights behind EP ranging from 2 to $3 \mathrm{~m}$ vertical, as seen in Figure 2. The constructed barrier was surveyed upon completion to determine the volume of material and final height. A load test frame was constructed and attached to a dozer to apply a force across a $4 \mathrm{~m}$ wide by $1 \mathrm{~m}$ high impact area through four $180 \mathrm{t}$ load cells across the frame (Figure 3). Using a Caterpillar 992 loader, the oxide and fresh rock materials were placed behind 24 individual EP modules covering a length of $48 \mathrm{~m}$. 

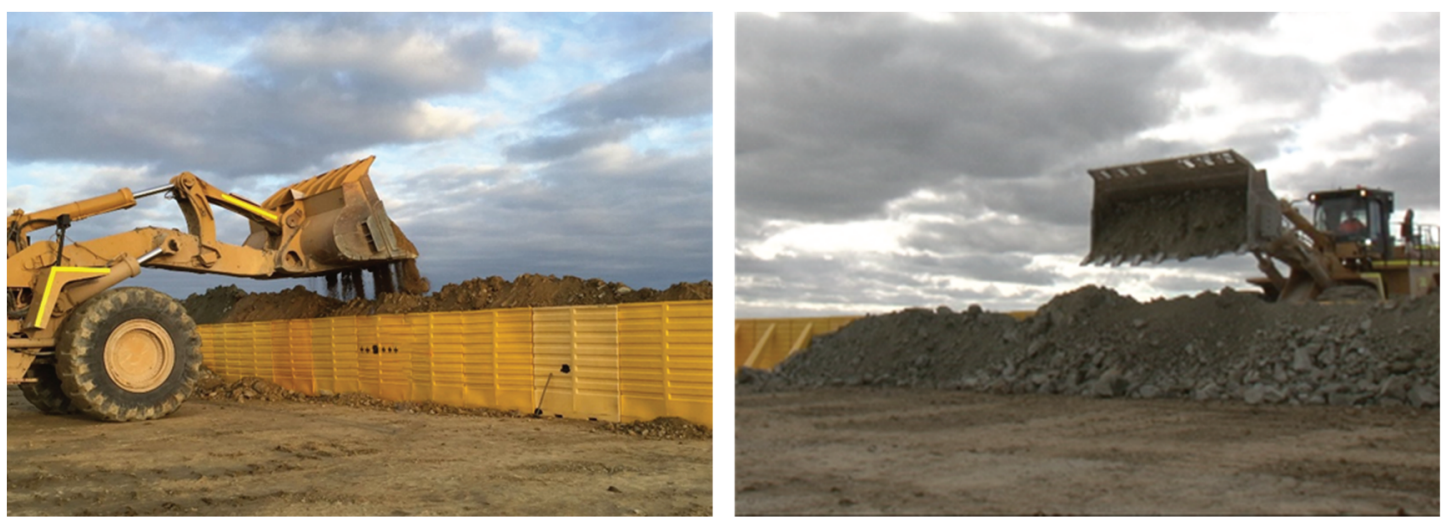

Figure 2 Creating the oxide and fresh rock bund

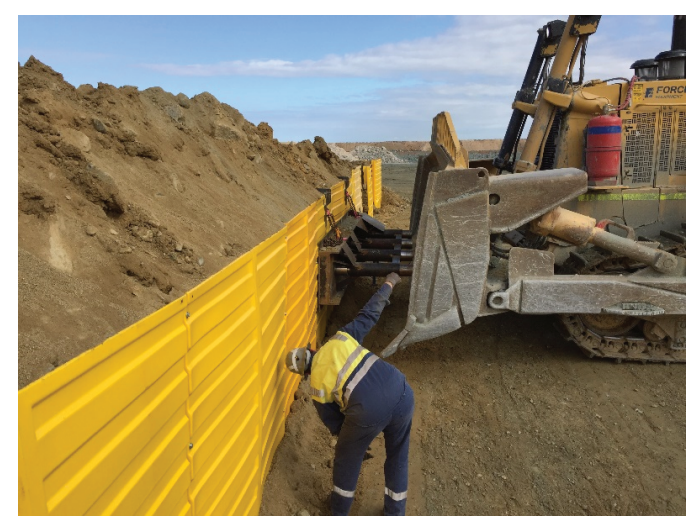

Figure 3 Edge Protector load test frame

Additional testing on the mathematical model was conducted at Penasquito Mine in Mexico where a $215 \mathrm{t}$ empty Komatsu 930E haul truck was used to demonstrate penetration distances using EP along a berm shown in Figure 4.
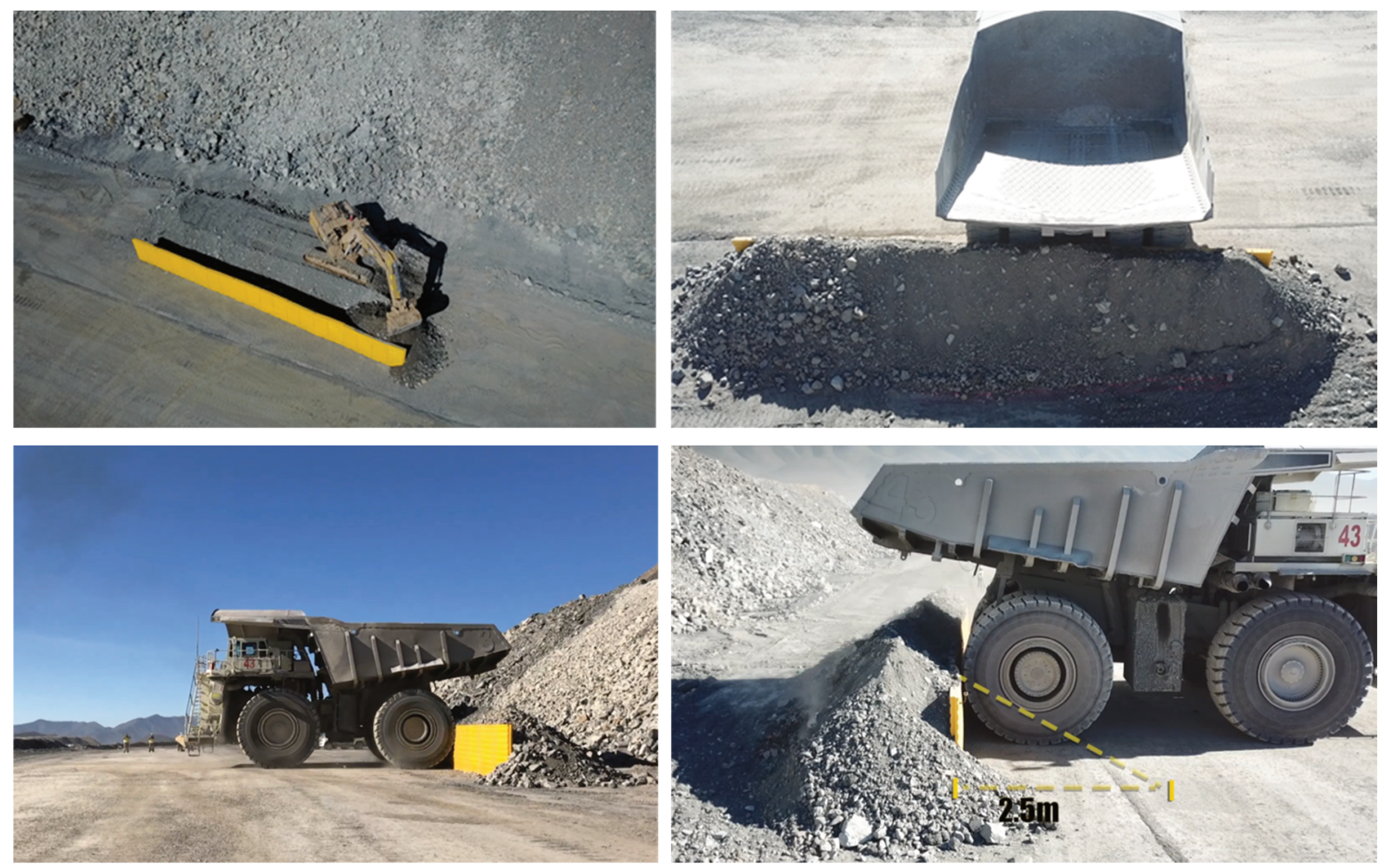

Figure 4 Komatsu 930E physical testing of Edge Protector 


\section{Results of case studies: safety and economic impact}

\subsection{Safety barriers}

Outputs from the (Fowkes \& Bassom 2015) numerical model suggest that upon impact, the EP will act as a moving barrier displacing the wedge of rock material behind the barrier and transfer a portion of the material up and over the wedge as overflow (Figure 5). To minimise the movement of EP on impact, resistive forces are required made up of two components: soil resistance acting at a right angle to the barrier and frictional resistance acting underneath the barrier and under the wedge of rock moving with the barrier. This theory also suggests that the resistive force of the barrier is independent of the impact speed of the truck and is applied immediately on impact.

The approach taken to apply the dozer force at a $90^{\circ}$ angle to the EP bund was to imitate a worst-case scenario on a mine site. In the event of an impact, EP alone would not stop or deflect a vehicle but the force applied to the EP and rock behind the barrier is what activates the soil resistive force on the vertical face. The critical shear stress required to move the rock is dependent on the rock type and composition as well as the volume. It is the height and weight of the rock supporting the barrier that will determine the success of the barrier.

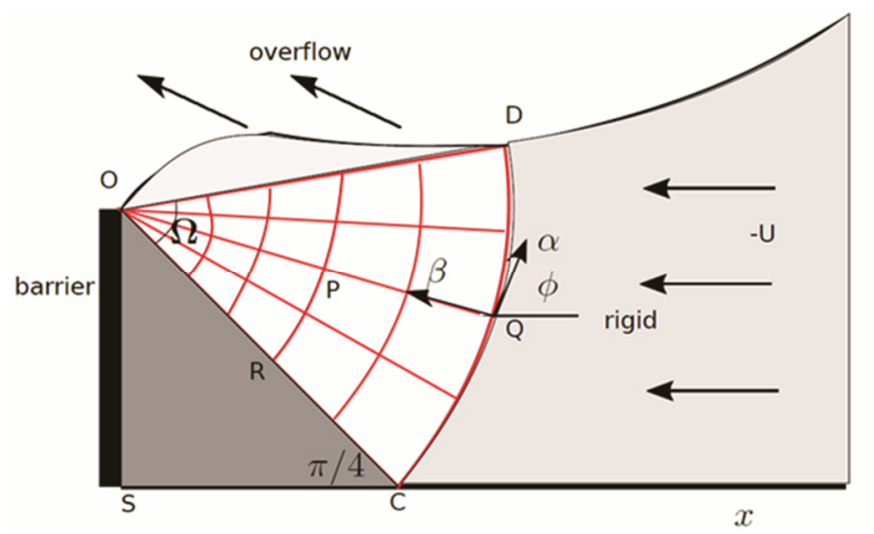

A sketch of the slip-line geometry within the frame which holds the barrier fixed. Slip occurs along the radial $\beta$ slip-lines depicted (the red lines). The dynamic pressure increases in the azimuthal $\alpha$ direction away from the rigid body/plastic zone junction along slip-line OC. Soil in the wedge OSC is at rest; that to the right of the arc CQD moves with velocity $-U$ to the left. Soil overflows and spills above the barrier as shown; the net flux into the plastic region over CQD is balanced by the net overflow flux across OD (Fowkes et al. 2017).

Figure 5 Slip-line geometry of Edge Protector bund

In a collision, it is impossible to accurately predict the response of the barrier and truck movement and momentum due to the complex geometry as well the various vehicle speeds and wheel orientations. The theoretical model and supporting calculations have concluded that if a truck hits the barrier at a given velocity at an oblique angle, the velocity will be reduced to zero from the barrier resistance. During this impact, the truck will slide along the barrier as a result of the tangential velocity and slow due to frictional forces. Once the normal velocity of the truck and barrier has returned to zero, the elastic rebound energy of the EP will cause the vehicle to travel at reduced speeds along the barrier.

Future experiments were conducted by (Fowkes et al. 2017) for oblique angle interactions. Results of the study indicate that an empty $200 \mathrm{t}$ truck travelling at a speed of $20 \mathrm{~km} / \mathrm{hr}$ with a normal impact angle perpendicular to an EP with a $2 \mathrm{~m}$ high rockfill would move the barrier approximately $4.2 \mathrm{~m}$. If the truck approached the same EP at a $20^{\circ}$ angle, the penetration distance would decrease to only $0.5 \mathrm{~m}$. Increasing the fill height to $3.2 \mathrm{~m}$ would further reduce the distance of a normal impact to $3 \mathrm{~m}$ and an oblique $20^{\circ}$ impact angle to $0.15 \mathrm{~m}$.

Physical testing was conducted using a $500 \mathrm{t}$ loader impacting two EP modules spanning $4 \mathrm{~m}$. Under impact, the EP was able to sustain the forces and provide movement to the rock behind the units. In the physical testing, the dozer was able to move and relocate EP with fill heights of $2.5 \mathrm{~m}$ and $2 \mathrm{~m}$. In areas that had a rock height of greater than $2.5 \mathrm{~m}$, the dozer was not able to apply enough tractive force to move the barrier. The maximum force reached was $600 \mathrm{kN}$ where the dozer lost traction. The physical testing values recorded may be lower than the actual forces for full mobilisation of EP. 
From the experiment, a $500 \mathrm{t}$ truck moving at a speed of $10 \mathrm{~km} / \mathrm{h}$ in a head-on collision would require a $2.5 \mathrm{~m}$ rock height to force a complete stop over $1.8 \mathrm{~m}$. With a smaller incidence angle of $20^{\circ}$, the penetration distance would be reduced to $0.2 \mathrm{~m}$. At a $20^{\circ}$ angle, increasing the rock height to $3.2 \mathrm{~m}$ would reduce the head-on collision penetration distance to $0.15 \mathrm{~m}$.

At Penasquito mine, a trained operator performed additional testing on EP. The $215 \mathrm{t}$ haul truck impacted the EP barrier at a speed of $5 \mathrm{~km} / \mathrm{h}$ resulting in a penetration distance of $0.15 \mathrm{~m}$ compared to the theoretical prediction of $0.17 \mathrm{~m}$. The test results confirm the validity of the mathematical model in place for EP.

\subsection{Stripping ratio}

Whittle Consulting Pty Ltd determined that applying EP units in a $440 \mathrm{~m}$ deep pit with a 1:10 descending haul road would reduce the haul road by $2.5 \mathrm{~m}$ in Case 1 and $5.0 \mathrm{~m}$ in Case 2 showing in Figure 6. The $2.4 \mathrm{~m}$ change in Case 1 is the result of the removal of one horizontal spread of the rockfill. Additional road reduction occurs in Case 2 from dropping the height and spread of the base case fill. By decreasing the horizontal spread in Case 1 a mean pit slope of $40.5^{\circ}$ was achieved in the analysis. In Case 2 the reduction of the fill height and width allowed for an increased mean pit slope of $41^{\circ}$ shown in Figure 7.
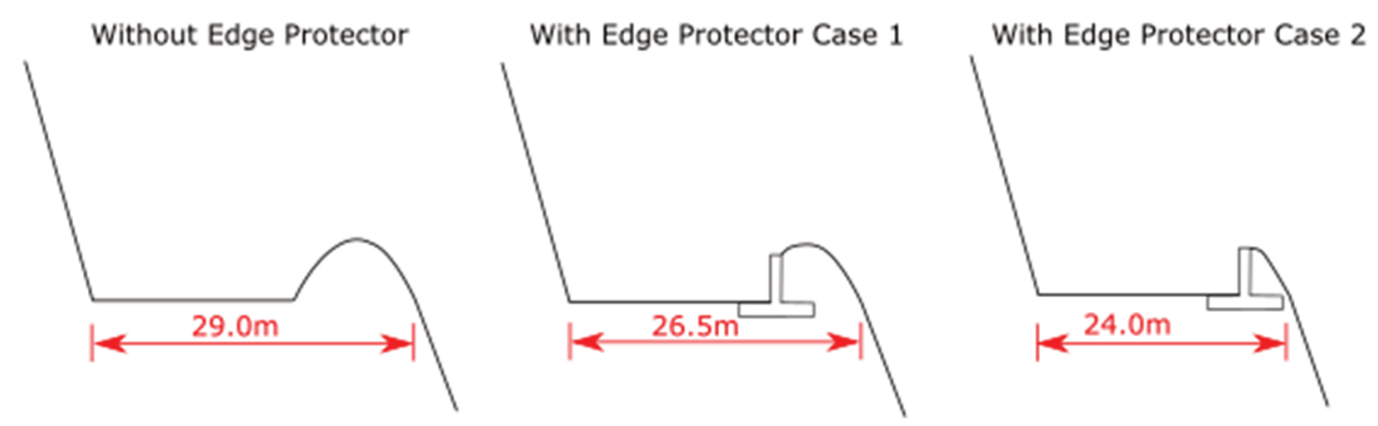

Figure 6 Comparison of a haul road width with and without Edge Protector (Redwood 2019)

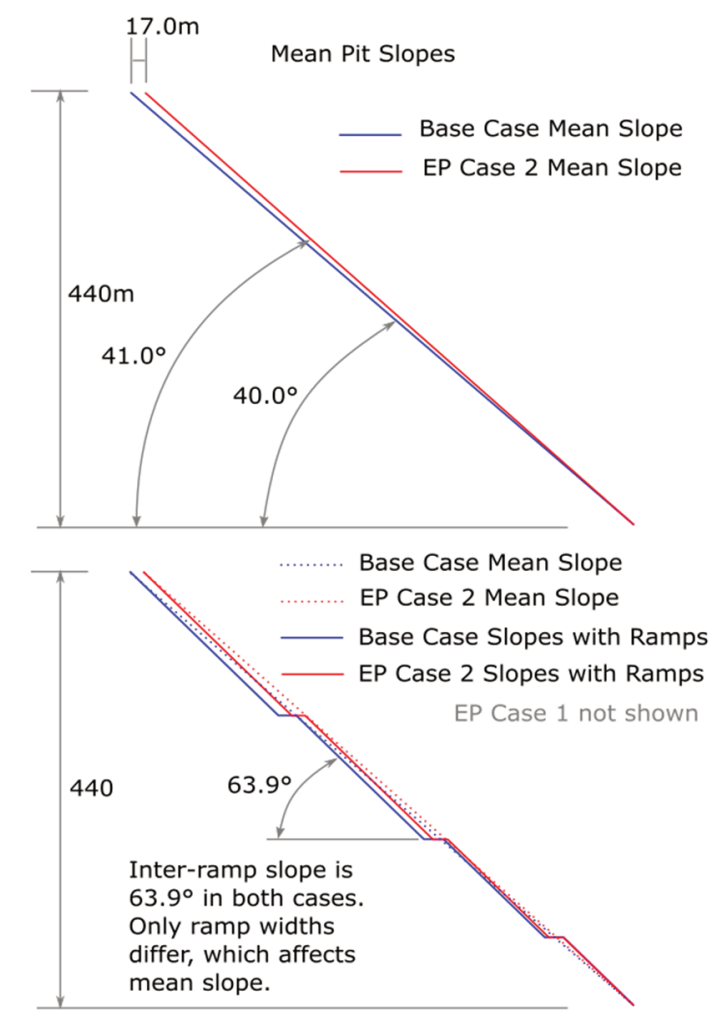

Figure 7 Diagram displaying the effect of ramp width over pit slopes 
Increasing the mean pit slope created a re-optimised smaller pit with $6.6 \mathrm{Mt}$ less mass than the modelled base case, though containing slightly less ore $(0.7 \mathrm{Mt})$ with the same copper and gold grade mined. For Case 1 , the stripping ratio was reduced by 0.028 from the base case due to the smaller pit size and increased slope.

Re-optimising the model using Case 2 parameters produced a larger pit than in EP Case 1 and the base case by 9.9 Mt and 3.3 Mt, respectively. A larger pit was generated from the increased mean pit slope allowing access to additional ore at the base of the pit. An additional $3.83 \mathrm{Mt}$ of ore was added to the mine development when compared to the base case and $4.5 \mathrm{Mt}$ more than Case 1. Increasing the pit size increases the total mass required to be mined and increases the stripping ratio to 0.893 , a 0.020 change from the base case. The added mining and processing costs associated with Case 2 is outweighed by a AUD 54.9 $\mathrm{M}$ discounted revenue.

The NPV of the models has been designated as the primary metric for comparing the three cases in the Whittle Consulting Pty Ltd, Edge Protector Financial assessment. The NPV was calculated from the sum of the mining and processing costs, cost of EP and the revenue and capital expenditure (Table 1). EP Case 1 has an NPV increase of AUD $8.1 \mathrm{M}$ revenue, reflective of the change in stripping ratio and the reduction of processing costs from the base case. EP Case 2 produced the highest NPV at AUD $18.6 \mathrm{M}$ above the base case. The high NPV is weighted dominantly on the additional revenue from newly accessible ore at the bottom of the pit.

Table 1 Summary of the differences in discounted cash between the three cases (in AUD)

\begin{tabular}{llllll}
\hline & Base $\left(\mathbf{4 0}^{\circ}\right)$ & EPC1 $\left(\mathbf{4 0 . 5}^{\circ}\right)$ & EPC2 $\left(\mathbf{4 1 . 0 ^ { \circ } )}\right.$ & Diff. EPC1 & Diff. EPC2 \\
\hline Mining costs & $-\$ 803.5$ & $-\$ 798.6$ & $-\$ 815.2$ & $\$ 4.9$ & $-\$ 11.7$ \\
Processing costs & $-\$ 1,489.4$ & $-\$ 1,485.7$ & $-\$ 1,507.5$ & $\$ 3.7$ & $-\$ 18.1$ \\
Revenue & $\$ 3,395.5$ & $\$ 3,401.3$ & $\$ 3,450.4$ & $\$ 5.8$ & $\$ 54.9$ \\
Edge protector costs & - & $-\$ 6.4$ & $-\$ 6.5$ & $-\$ 6.4$ & $-\$ 6.5$ \\
Capital & $-\$ 600.0$ & $-\$ 600.0$ & $-\$ 600.0$ & - & - \\
Net present value & $\$ 502.5$ & $\$ 510.6$ & $\$ 521.1$ & $\$ 8.1$ & $\$ 18.6$ \\
$\mathrm{CO}_{2}$ emissions $(\mathrm{Mt}) *$ & 1918 & 1,875 & 1926 & $-2.2 \%$ & $0.4 \%$ \\
$\mathrm{CO}_{2}$ emissions $(\mathrm{Mt} / \$)^{*}$ & 3.82 & 3.67 & 3.70 & $-3.8 \%$ & $-3.1 \%$ \\
\hline
\end{tabular}

*Mining fleet diesel $\mathrm{CO}_{2}$ only

\subsection{Resource access}

\subsubsection{Mining rate}

Case 1 increases the mining rate from the presence of EP reducing the stripping ratio so that each bench is mined with significantly less waste reducing the overall mining costs. The increased pitwall slope angle and mined waste saving allow for faster mine development and turnover of processed ore. Even though the total cash revenue is less than the base case over the life of mines, the revenue is generated earlier and has a greater discounted value.

A steeper pitwall slope in Case 2 created a larger and deeper pit when compared to the base case, increasing both the mining and processing costs. These costs, however, are offset by the increase in discounted revenue from the supplementary ore. It is the additional ore, but not the impact on the stripping ratio and mining rate in Case 2, that influences the surge in NPV. 


\subsection{Mine fleet}

\subsubsection{Increased fleet size}

An alternative application for EP is to maintain or widen haul roads by reducing planned or existing traditional rock bunds. Wider roads allow sites to increase their safety barrier protection and continue running an existing fleet with increased confidence or perhaps run larger trucks in the operation. This option allows mines to have flexibility in determining fleet size in a greenfield project or adapting an existing fleet program to increase efficiency.

Mining costs may be lowered from the use of larger haul trucks onsite. Larger trucks would mean fewer trucks required to transport the same volume of ore. Fewer trips for each vehicle would be required to transport ore from the bottom of the pit to a processing plant. Fewer trucks would, in turn, reduce the number of operators required onsite to move resource material.

\subsubsection{Autonomous haulage systems}

A focus on safety and operating costs has led many mine sites to operate autonomous haulage systems (AHS) in their mining fleet. AHS systems rely on up to date mine maps and sensors (primarily RADAR and LiDAR sensors) on moving mining equipment to determine vehicle movement paths. These sensors are in place to detect external objects including vehicles, sidewalls, windrows and bunds along the haulage path to keep the vehicle moving along a constant and consistent route or permission line. A smooth surface is ideal and minimises the number of objects detected by the sensors, though irregular terrains can be mapped with more difficulty in delineating a transit mine map.

Frequent delays or stoppages of AHS mining equipment is prominently a result of obstacle detection on haul roads or irregularities of the operating systems. Implementation of EP in a mine site is likely to aid in the confidence of the AHS system by creating a smooth and consistent surface to avoid sensor detection. The presence of an increased or dependable road width and barrier produced by EP may allow AHS vehicles to pass closer to one another and/or travel closer to the pit wall or windrow side and perhaps create adequate space for an overtaking zone.

\section{$4 \quad$ Results of case studies: environmental impact}

\section{1 $\mathrm{CO}_{2}$ emissions}

Whittle Consulting Pty Ltd concluded that the use of EP would impact the stripping ratio and total mined waste in the modelled cases which have implications for the $\mathrm{CO}_{2}$ emissions produced during the life-of-mine. Carbon dioxide emissions decreased by $2.2 \%$ (Table 2 ) from the base case to Case 1 . This is a result of a reduction in the total mass mined of $1.8 \%$ and the distance of mass moved reduced by $2.3 \%$. By using EP in this scenario, the $\mathrm{CO}_{2}$ emissions were reduced by a total of approximately $43,000,000 \mathrm{t}$. This amount according to the United States Environment Protection Agency is equivalent to $9.13 \mathrm{M}$ passenger vehicles removed from the road for a year, as seen in Figure 8.

Greenhouse gas emissions from

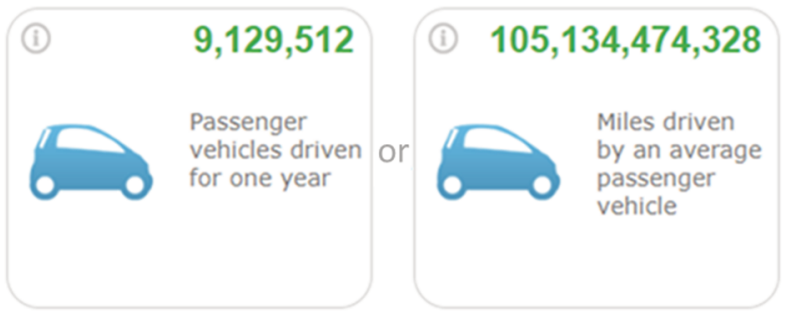

$\mathrm{CO}_{2}$ emissions from

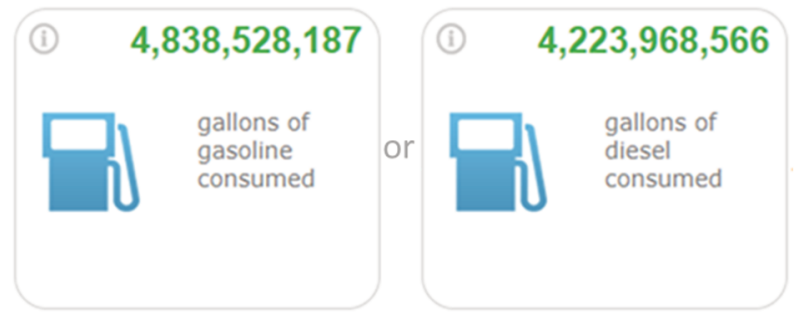

Figure 8 Equivalence of the greenhouse gas emissions of $43,000,000 \mathrm{t}$ of $\mathrm{CO}_{2}$ (United States Environmental Protection Agency 2019) 
Table 2 Whittle Consulting Pty Ltd results on the impact of Edge Protector on the mine development of the three case studies (in AUD)

\begin{tabular}{|c|c|c|c|c|c|}
\hline & Base $\left(40^{\circ}\right)$ & EPC1 $\left(40.5^{\circ}\right)$ & Diff. EPC1 & $\operatorname{EPC2}\left(41.0^{\circ}\right)$ & Diff. EPC2 \\
\hline \multicolumn{6}{|l|}{ Pit contents } \\
\hline Mass (Mt) & 364.3 & 357.7 & -6.6 & 367.6 & 3.3 \\
\hline $\mathrm{Cu}(\mathrm{kt})$ & $1,447.6$ & $1,440.9$ & -6.7 & $1,474.8$ & 27.3 \\
\hline Mean Cu grade (\%) & $0.397 \%$ & $0.403 \%$ & $0.006 \%$ & $0.401 \%$ & $0.004 \%$ \\
\hline $\mathrm{Au}(\mathrm{kTr} . \mathrm{Oz})$ & 3,464 & 3,455 & -10 & 3,516 & 52 \\
\hline Mean Au grade $(\mathrm{g} / \mathrm{t})$ & 0.296 & 0.300 & 0.005 & 0.298 & 0.002 \\
\hline Mining costs (\$M) & $-\$ 1,184.1$ & $-\$ 1,162.4$ & $\$ 21.6$ & $-\$ 1,194.8$ & $-\$ 10.8$ \\
\hline Mining costs (disc. \$M) & $-\$ 803.5$ & $-\$ 798.6$ & $\$ 4.9$ & $-\$ 815.2$ & $-\$ 11.7$ \\
\hline \multicolumn{6}{|l|}{ EP costs } \\
\hline EP costs (\$M) & & $-\$ 8.4$ & $-\$ 8.4$ & $-\$ 8.8$ & $-\$ 8.8$ \\
\hline EP costs (disc. \$M) & & $-\$ 6.4$ & $-\$ 6.4$ & $-\$ 6.5$ & $-\$ 6.5$ \\
\hline \multicolumn{6}{|l|}{ Ore } \\
\hline Mass (Mt) & 190.37 & 189.6 & -0.7 & 194.2 & 3.8 \\
\hline $\mathrm{Cu}(\mathrm{kt})$ & $1,282.1$ & $1,277.8$ & -4.3 & $1,307.4$ & 25.3 \\
\hline Mean CU grade (\%) & $0.673 \%$ & $0.674 \%$ & $0.000 \%$ & $0.673 \%$ & $0.000 \%$ \\
\hline $\mathrm{Au}(\mathrm{kTr} . \mathrm{Oz})$ & 3,066 & 3,061 & -5.4 & 3,115 & 48.8 \\
\hline Mean Au grade $(\mathrm{g} / \mathrm{t})$ & 0.501 & 0.502 & 0.001 & 0.499 & -0.002 \\
\hline Stripping ratio & 0.914 & 0.886 & -0.028 & 0.893 & -0.020 \\
\hline Processing costs (\$M) & $-\$ 2,379.1$ & $-\$ 2,369.6$ & $\$ 9.5$ & $-\$ 2,426.3$ & $-\$ 47.2$ \\
\hline Processing costs (disc. \$M) & $-\$ 1,489.4$ & $-\$ 1,485.7$ & $\$ 3.7$ & $-\$ 1,507.5$ & $-\$ 18.1$ \\
\hline \multicolumn{6}{|l|}{ Product } \\
\hline $\mathrm{Cu}(\mathrm{kt})$ & 794.4 & 790.6 & -3.8 & 811.5 & 17.0 \\
\hline $\mathrm{Au}(\mathrm{kTr} . \mathrm{Oz})$ & 2,386 & 2,381 & -5.0 & 2,425 & 38.5 \\
\hline \multicolumn{6}{|l|}{ Revenue (less sell costs) } \\
\hline Revenue (\$M) & $\$ 5,239.9$ & $\$ 5,222.0$ & $-\$ 18.0$ & $\$ 5,338.1$ & $\$ 98.2$ \\
\hline Revenue (disc. M) & $\$ 3,395.5$ & $\$ 3,401.3$ & $\$ 5.8$ & $\$ 3,450.4$ & $\$ 54.9$ \\
\hline \multicolumn{6}{|l|}{ Capital } \\
\hline Capital (\$M) & $-\$ 600.0$ & $-\$ 600.0$ & & $-\$ 600.0$ & \\
\hline Net present value & $\$ 502.5$ & $\$ 510.6$ & $\$ 8.1$ & $\$ 521.1$ & \$18.6 \\
\hline
\end{tabular}

The $\$ 18.6 \mathrm{M}$ improvement in net present value (NPV) from EP Case 2 can be seen as: $\triangle N P V=$ mining cost reduction + (revenue increase - processing cost increase) $-E P$ cost.

The $\mathrm{CO}_{2}$ emissions will not always decrease in association with EP. If the goal of mine optimisation is to increase the mean pit slope targeting accessible ore at the base of the pit there will not be a reduction in the emission levels. This is what occurred in Case 2 where the increased pit slope produced a larger pit size and increased emissions. To combat $\mathrm{CO}_{2}$ emissions during the life-of-mine, the initial design of the mine would need to be optimised to match a specific $\mathrm{CO}_{2}$ target. In both cases, the emissions are reduced as a factor of metal production which should be the important metric. 


\section{$5 \quad$ Discussions}

Safescape EP was developed to increase the safety of open pit mines by replacing traditional rock bunds and challenging the existing guidelines regarding berm construction on mine sites. Current guidelines vary between state legislation but generally suggest that edge protection is the responsibility of the operator to ensure 'adequate' or 'appropriate' protection to prevent a vehicle from going over the edge. The level of protection acceptable is frequently stated as a minimum bund height ranging between half to two-thirds of the diameter of the largest truck tyre used by the operator. In Mining Haul Roads - Theory and Practice (Thompson et al. 2019), the height of the safety berm is suggested to be as steep as possible with a recommended ratio of $1.5 \mathrm{~V}: 1 \mathrm{H}$ with consolidated material as unconsolidated rock will not support the ratio.

Even with an 'adequate' bund in place, operator-driven trucks often hit and breach these barriers with some coming to a stop in the bund and some rolling over the edge to varying degrees of severity. Incidents occur due to many factors including environmental conditions, road conditions, operator error or inadequate bunding in place.

Proposed solutions to fatalities or near-miss incidents concerning a berm and pit edge often include suggesting higher and wider barriers to the high-risk areas. An alternative outlook is taken by the Mine Safety and Health Administration in the United States who encourage vehicle operators to consider rock bunds as an indicator of an edge or drop-off rather than a safety barrier as a preventative measure.

There is no scientific evidence to suggest implementing higher bunds would reduce or prevent the risk of trucks going above the bund and over the edge of a pit. Additionally, no proportional bund height to truck size ratio has been suggested to improve the high-risk areas. Increasing traditional bund heights would naturally increase the width of the berms required and thus widen the overall width of the roads raising the stripping ratio. Higher berms do not necessarily reduce the chance of a rollover event and often result in trucks tipping over as they breach the berm causing an ulterior incident event.

EP creates a vertical face barrier that prevents truck tyres from rolling up the barrier and encourages vehicles to push against the barrier instead of up and over a traditional bund. The model developed for stopping distance suggests that the main factor in the resistive forces acting on the truck arise from the rock support. The movement and heaving of the rockfill are what generate the resistive force triggered by the transition of energy from the impact on the EP units. The physical results support this theory and produce similar stopping distances to the theoretical calculations.

An essential conclusion from the physical and theoretical studies is that the resistant force to rockfill movement seems to be velocity-independent with resistive forces increasing rapidly with fill height and composition. The resistant force is a product of the shear stress required to move the EP barrier, which is rock composition and depth-dependent, with the hydrostatic component of the stress dominating. The effectiveness of EP is, therefore, a function of the composition and height of the rock that supports the barrier.

EP has proven to withstand a worst-case scenario impact and impacts at smaller approach angles at varying speeds in the theoretical and physical testing. In both cases, EP and the bund will move and apply forces back onto the vehicle before arresting the vehicle or deflecting it back onto the road. The physical testing supported the theoretical calculations permitting the model to be used as a predictive tool.

EP has been included as an example of best practice for safety berms in Mining Haul Roads - Theory and Practice (Thompson et al. 2019) due to the design, ability to reduce the footprint of a berm and prevention of trucks from breaching a berm.

With these safety factors in mind, an economic advantage is associated with the use of the EP product. Positive economic results stem from the capability of the product to reduce the width requirements of the pit ramp and increase the pitwall overall slope angle. The change in the angle of the slope may not initially appear significant but the effects are evident in the NPV and $\mathrm{CO}_{2}$ emissions of the evaluated case studies.

The use of EP in the theoretical case studies provided a significant improvement in NPV to AUD $8 \mathrm{M}$ in Case 1 and AUD $18 \mathrm{M}$ in Case 2. NPV improvement in Case 1 is achieved by decreasing the width of the haul roads 
and thus the stripping ratio during mine development. A smaller stripping ratio requires less waste to be removed during development, acceleration through the orebody and earlier revenue in the life-of-mine. If EP is considered in a greenfield project the mine plan can be designed using the smaller roads and reap the benefits of EP from the beginning.

Case 2 added further value to the project but in this case, it was not attributed to reduced material movement from the steeper pitwall and stripping ratio, but instead from access to additional ore at the bottom of the pit. In summary, in Case 1 it was more economical to reduce the stripping ratio where in Case 2 it was more beneficial to target additional ore even though it was accompanied by additional waste removal costs.

Using EP to reduce haul road widths, stripping ratio and the waste removed will have a direct impact on the $\mathrm{CO}_{2}$ emissions produced by mine operation. However, increasing a pitwall slope angle does not always correlate with a decrease in emission if the change in slope is used to mine deeper into the orebody. The benefits of re-optimising the mine design to consider implementing EP to directly target mine emissions would be mine specific and should be assessed early in development.

For mines currently in operation, EP can aid in maintaining or increasing the current haul road widths. Wider roads have the potential to support larger haul trucks reducing the number of fleet vehicles and the number of trips required for production potentially increasing the NPV. An alternative change in haul fleet to autonomous vehicles may be favourable by specific mine sites supported by the increased confidence in sensor detection of an EP barrier wall.

\section{Conclusion}

EP increases the safety and confidence of truck operators in open cut mines. The design exceeds the 'adequate' bunding requirements set by mining regulators and has been theoretically and physically proven to arrest or deflect mining vehicles. When used, EP has the potential to reduce fatalities and near-miss incidents caused by vehicles breaching traditional bunds.

The pitwall slope in an open pit mine determines the size and stripping ratio of the development relative to the orebody. EP has the potential to reduce the stripping ratio throughout mine development and increases the ore reserve and NPV of the project. In addition, EP creates a potential opportunity to access additional ore deeper in the pit and increase revenue. Cost savings may also be present for existing operations by decreasing the size of the traditional bunds onsite and by changing the existing fleet to more economical options.

Investigation of the environmental impact of EP indicated that the use of the product to increase the pitwall slope angle will decrease the $\mathrm{CO}_{2}$ emissions of vehicles by operating within a smaller mine and by removing less waste during the life-of-mine.

EP has clear safety, economic and environmental benefits for open pit mine sites.

\section{References}

Durkin, S, Fowkes, N, Redwood, N \& Bassom, AP 2016, 'Innovative Approach to Open Pit Edge Protection', in M Goodz (ed.), Proceedings of the Ninth AusIMM Open Pit Operators' Conference, AusIMM The Minerals Institute, Carlton, pp. 138-149.

Geovia Whittle ca. 2019, Strategic Mine Planning - Optimise Mine Profits, computer software, https://www.3ds.com/products-services/geovia/products/whittle/

Fowkes, N \& Bassom, A 2015, Dump truck safety barriers: a report for Safescape, Safescape, internal document.

Fowkes, N, Durkin, S \& Bassom, A 2017, 'Truck safety barriers for mining sites', The ANZIAM Journal, vol. 59, issue 1, pp. 35-50, doi:10.1017/S1446181117000281

Redwood, N 2019, Edge Protector Financial assessment, Whittle Consulting Pty Ltd, internal document.

Redwood, N 2018, Autonomous Haulage Systems Financial Model Assessment: Revision F, Whittle Consulting Pty Ltd, Surrey Hills.

Redwood, N 2016, Edge Protector Financial assessment, Whittle Consulting Pty Ltd, internal document.

Thompson, R, Peroni, R \& Visser, A 2019, Mining Haul Roads: Theory and Practice, CRC Press, London.

United States Environmental Protection Agency 2019, Greenhouse Gas Equivalencies Calculator, https://www.epa.gov/energy /greenhouse-gas-equivalencies-calculator 
